\title{
Separation of Cyclotron Produced In-1 11 (III) from Cadmium (II) and Copper (II) Ions Using Ion Exchange Technique in Different Media
} Hanafi HA ${ }^{1,3 *}$ and Abd El-Samad $\mathbf{M}^{1,2}$

${ }^{1}$ Cyclotron Project, Nuclear Research Center, Atomic Energy Authority, Egypt

${ }^{2}$ Radiated Pollution Department, Hot Laboratories Center, Atomic Energy Authority, Egypt

${ }^{3}$ College of Science and Humanities, Al-Quwayiyah, Shaqra University, Saudi Arabia

\begin{abstract}
The commercial cation exchangers TSKgel BioAssist S, TSKgel CM-2SW and TSKgel CM-STAT have been used for the separation of ${ }^{111} \mathrm{In}$ (III) from Cd (II) and Cu (II) ions. The separation was carried out using low cost cation exchangers based on the differences in the sorption affinity of $\mathrm{In}, \mathrm{Cu}$ and $\mathrm{Cd}$ towards the ion exchanger from $0.01 \mathrm{~mol}$ $\mathrm{L}^{-1} \mathrm{HCl}$. The effects of various parameters such as shaking time, $\mathrm{HCl}$ concentration and acetate buffer concentration were examined. A comparative study between cation exchangers showed the best one for radiochemical separation yielded more than $98 \%$ within 50 min by using column study.
\end{abstract}

Keywords: Cation exchangers; Radioindium; Separation; Hydrochloric acid; Cadmium; Copper; Column study

\section{Introduction}

Indium-111 or ${ }^{111}$ In is one of the most important radioactive elements which are used in nuclear medicine. It is used for surveying in vivo cell distribution in various contexts such as brain tumors and myocardial damage detections [1].

Several techniques have been identified for separation of In111 from Cd target using different types of cation exchangers [1]. The sorption behavior of ${ }^{111} \mathrm{In}$ and ${ }^{111} \mathrm{Cd}$ on cation exchangers was investigated at different molarities of $\mathrm{HCl}$; the sorption capacity of $\mathrm{Cd}$ on a cation exchanger was higher than on an anion exchanger.

A chromatography method using inorganic exchange and organic exchange Doex and Amberlit was described [2]. Sorption of ${ }^{111} \mathrm{Cd}$ and ${ }^{115 m}$ In by organic ion exchangers was studied at different molarities of hydrochloric acid the sorption capacity of $\mathrm{Cd}$ on a cation exchanger was higher than on an anion exchanger [3].

${ }^{111}$ In has been amongst the frequently used radionuclides in diagnostic nuclear medicine. Therefore, its production and subsequent separation chemistry have been widely investigated since the late 40 s. Indium is a rare element evenly distributed in the earth crust. It has no material of its own character. Therefore, it has to be recovered as byproduct from other metallurgical process, most commonly associated with copper, zinc and tin. Indium and its compounds have been found in wastewater discharged from optoelectronic plants and they are suspected to be carcinogenic to humans, therefore, the removal of In (III) ions from aqueous solutions has become a significant subject [4].

The proton or $\alpha$-particle induced reactions on cadmium or silver targets are the most common production techniques for ${ }^{111} \mathrm{In}$. Recently, production using various activation routes of heavier ions such as ${ }^{7} \mathrm{Li}$, ${ }^{11} \mathrm{~B},{ }^{12} \mathrm{C}$ have been proposed.

A portray for the production routes of ${ }^{111}$ In and chemical separation methodologies has been reported [4-6]. Also, ${ }^{111}$ In was produced from an irradiated natural cadmium target using AG 1-X8 anion exchanger under various conditions.

A simple and reliable way of ${ }^{111}$ In production with the highest radionuclide purity from its grandparent ${ }^{111} \mathrm{Sb}$ and parent ${ }^{111} \mathrm{Sn}$ nuclei, produced by the ${ }^{112} \mathrm{Sn}(\mathrm{p}, 2 \mathrm{n}){ }^{111} \mathrm{Sb}$ and ${ }^{112} \mathrm{Sn}(\mathrm{p}, \mathrm{pn}){ }^{111} \mathrm{Sn}$ reactions, respectively.
Conventional techniques were reported for separation of In111 from Cd target using different types of cation exchangers [7], and synthetic polymeric resins [8]. A chromatographic method using inorganic ion exchanger (zirconium oxide) for radiochemical separation of non-carrier added In-115 from Cd-115 over a column of zirconium oxide was described [9]. Recently, numerous alternative techniques have been examined for the separation of indium from cadmium and copper using silica extracted agricultural wastes. Column separation technique is widely applied to separate ${ }^{111} \mathrm{In}$ from interfering ions based on the evaluation of distribution coefficient $\mathrm{K}_{\mathrm{d}}$.

Modern separation techniques for separation of $\mathrm{Ga}$ (II) using poly(acrylamide-acrylic acid disodium EDTA) were studied. The prepared inorganic ion exchangers used separation of radioactive elements such as cesium [10].

In the present work we investigated the possibility of using cation exchangers for separation of radioindium from cadmium and copper, the distribution coefficients of the three elements on different types of cation exchangers were measured in $0.01 \mathrm{M} \mathrm{HCl}$, acetate buffer at $\mathrm{pH} 4$ and EDTA $\left(10^{-3} \mathrm{M}\right)$ to find the best conditions for separation.

\section{Materials and Methods}

\section{Materials}

Indium metal (99.9\% purity,), anhydrous cadmium chloride $\left(\mathrm{CdCl}_{2}\right)$, cupric chloride dehydrate $\left(\mathrm{CuCl}_{2} \cdot 2 \mathrm{H}_{2} \mathrm{O}\right)$, sodium hydroxide $(\mathrm{NaOH})$, anhydrous sodium acetate $\left(\mathrm{CH}_{3} \mathrm{COONa}\right)$, Diethylene Tetramine Penta Acetic acid (DTPA), and Ethylene Diamine Tetra Acetic acid (EDTA) were reagent grade chemicals and supplied by Merck (Darmstadt, Germany).

*Corresponding author: Hanafi HA, Assistant Professor, Cyclotron Project, Nuclear Research Center, Atomic Energy Authority, Egypt and College of Science, Shaqra University, Kingdom of Saudi Arabia, E-mail: white_heart200014@yahoo.com

Received April 25, 2016; Accepted May 18, 2016; Published May 25, 2016

Citation: Hanafi HA, El-Samad AM (2016) Separation of Cyclotron Produced In-111 (III) from Cadmium (II) and Copper (II) lons Using lon Exchange Technique in Different Media. Chem Sci J 7: 130. doi:10.4172/2150-3494.1000130

Copyright: (C) 2016 Hanafi HA, et al. This is an open-access article distributed under the terms of the Creative Commons Attribution License, which permits unrestricted use, distribution, and reproduction in any medium, provided the original author and source are credited. 
TSKgel BioAssist S strong cation echanger, TSKgel CM-2SW (strong or weak exchangers) and TSKgel CM-STAT cation exchanger chromatography, with a mesh size within $50-100 \mu \mathrm{m}$ was received from Merck. The In-111 radioisotope was obtained by irradiation of cadmium-111 target ${ }^{111} \mathrm{Cd}(\mathrm{p}, \mathrm{n}){ }^{111} \mathrm{In}$ in $20 \mathrm{Mev}$ cyclotron at Inshas city (Cairo, Egypt).

\section{Methods}

Preparation of standard solutions: A standard solution contains $1000 \mu \mathrm{g} \mathrm{mL} \mathrm{m}^{-1}$ of indium was obtained by dissolving an accurately weighed amount of $1 \mathrm{~g}$ of pure indium metal in concentrated $\mathrm{HCl}$ $(36 \% \mathrm{v} / \mathrm{v})$. The mixture was left for $24 \mathrm{~h}$ till complete dissolution, the remaining acid was evaporated then the solution was diluted to 1000 $\mathrm{ml}$ by double distilled water.

Stock solutions containing $1000 \mathrm{mg} \mathrm{L}^{-1}$ from cadmium and copper were prepared by dissolution of $1.631 \mathrm{~g}$ of $\mathrm{CdCl}_{2}$ or $2.73 \mathrm{~g}$ of $\mathrm{CuCl}_{2} \cdot 2 \mathrm{H}_{2} \mathrm{O}$ in $1000 \mathrm{~mL}$ measuring flask using double distilled water.

Preparation of buffer solutions: Make up the following solutions

(1) $0.1 \mathrm{M}$ acetic acid

(2) $0.1 \mathrm{M}$ sodium acetate (tri-hydrate) $(13.6 \mathrm{~g} / \mathrm{l})$

Mix in the following proportions to get the required $\mathrm{pH}$

\begin{tabular}{|c|c|c|}
\hline $\mathbf{p H}$ & $\begin{array}{c}\text { Vol. of } \mathbf{0 . 1 M} \\
\text { Acetic acid }\end{array}$ & $\begin{array}{c}\text { Vol. of 0.1M } \\
\text { Sodium acetate }\end{array}$ \\
\hline 3 & $982.3 \mathrm{ml}$ & $17.7 \mathrm{ml}$ \\
\hline 4 & $847.0 \mathrm{ml}$ & $153.0 \mathrm{ml}$ \\
\hline 5 & $357.0 \mathrm{ml}$ & $643.0 \mathrm{ml}$ \\
\hline 6 & $52.2 \mathrm{ml}$ & $947.8 \mathrm{ml}$ \\
\hline
\end{tabular}

Preparation of EDTA solutions: Stir $186.1 \mathrm{~g}$ disodium ethylenediamine tetraacetate $2 \mathrm{H}_{2} \mathrm{O}$ into $800 \mathrm{ml}$ of distilled water.

Stir the solution vigorously using a magnetic stirrer.

Add $0.1 \mathrm{M} \mathrm{HCl}$ solution to adjust the $\mathrm{pH}$ to 4.0 . The EDTA will slowly go into solution as the $\mathrm{pH}$ of the solution nears 4.0.

Dilute the solution to $1 \mathrm{~L}$ with distilled water.

Filter the solution through a 0.5 micron filter.

Separation experiments: Separation of radioindium from Cd and copper ions was carried out using different cation exchangers at room temperature. Experiments were carried in five clean and dry penicillin bottles. For this purpose, an amount of $100 \mathrm{mg}$ of the cation exchanger was placed in each bottle and an aliquot equivalent to $1000 \mu \mathrm{g}$ of Cd or $\mathrm{Cu}$ was added. To each bottle, an accurate amount corresponding to a count (3.7 MBq) of In-111 was added. The final mixture was prepared in $10 \mathrm{~mL} \mathrm{HCl}$ at different concentrations $\left(0.05,0.1,0.5,1\right.$ and $\left.2 \mathrm{~mol} \mathrm{~L}^{-1}\right)$. After attaining equilibrium time, an aliquot of the aqueous phase was taken and analyzed for radioactivity of In-111 (Aaq.) and compared to an initial solution $\left(\mathrm{A}_{\mathrm{I}}\right)$. The distribution coefficient $\left(\mathrm{K}_{\mathrm{d}}\right)$ for indium was calculated according to the following equation [11-14]:

$$
K_{d}=\left[\frac{A i-A a q}{A a q}\right] \times \frac{V}{m}
$$

Where, $\mathrm{V}$ is the volume of the aqueous phase in $\mathrm{ml}$ and $\mathrm{m}$ is the mass of the ion exchanger in g. Cadmium and copper were determined spectrophotometrically in the solution using the method of atomic absorption and their distribution coefficients were determined. In these experiments the concentration of cadmium and copper was found to be 0.91 and $1.5 \mathrm{~mol} \mathrm{~L}^{-1}$, respectively.

\section{Results and Discussion}

\section{Batch experiments}

Effect of shaking time: The first batch experiment included the aqueous phase with reasonable count of radioindium in $0.05 \mathrm{~mol} \mathrm{~L}^{-1}$ $\mathrm{HCl}$ and CMcation exchangers as solid phase extractor using the strong cation exchanger TSKgel BioAssist $\mathrm{S}$ and two weak cation exchangers TSKgel CM-2SW and TSKgel CM-STAT.

The samples were shaken for different time intervals of times, a $1 \mathrm{~mL}$ aliquot from the aqueous phase was pipetted out and the concentration of ${ }^{111}$ In was determined using the gamma counter. The uptake of ${ }^{111} \mathrm{In}$ during each interval of shaking was determined according to Figure 1. It can be seen that, the uptake of indium increased with shaking time, reaching a plateau within $80 \mathrm{~min}$. corresponding to sorption or uptake of 65, 85 and 92\% for TSKgel BioAssist S, TSKgel CM-2SW and TSKgel CM-STAT, respectively.

A similar sorption profile was observed in case of TSKgel CM-2SW and TSKgel CM-STAT exchangers while the TSKgel BioAssist $S$ profile was always at lower sorption (\%). This indicates the better accessibility of the first two exchangers than the latter and accordingly, the stability of ${ }^{111}$ In is expected to be higher with the first two exchangers than the latter one.

Effect of hydrochloric acid concentration: The influence of acid concentration of the sorption $\mathrm{Cd}, \mathrm{Cu}$ and ${ }^{111}$ In was studied. Maximum sorption of the three elements was achieved at a concentration of 0.05 mol L-1 $\mathrm{HCl}$ solution on the cation exchangers as shown in Figures 2-4. It can be observed that, the sorption or uptake of ions decreased sharply with increasing the acid concentration. The high sorption values at concentration $0.05 \mathrm{~mol} \mathrm{~L}^{-1}$ could be due to capability of metal exchange at low acidity [13], which can be exchanged with $3 \mathrm{H}^{+}, 2 \mathrm{H}^{+}$ and $2 \mathrm{H}^{+}$ions of the resin. On other hand, the decrease in the sorption at high concentration of the acid can be attributed to the formation of various species of indium chloride complexes, e.g., $\mathrm{In}_{4}{ }_{4}^{-}, \mathrm{In} \mathrm{Cl}_{5}^{-2}$ and In $\mathrm{Cl}_{6}^{-3}$, cadmium chloride complexes e.g., $\mathrm{Cd} \mathrm{Cl}^{-3}, \mathrm{Cd} \mathrm{Cl}^{-2}$ and tetra chloro copperate $\mathrm{Cu} \mathrm{Cl}_{4}^{-2}$. Another plausabile interpretation could be due to the distribution of the studied metal ions is controlled by the solution $\mathrm{pH}$. At high acidity, the $\mathrm{H}^{+}$ions may compete with metal ions on the adsorption sites of the exchangers by decreasing the extent of

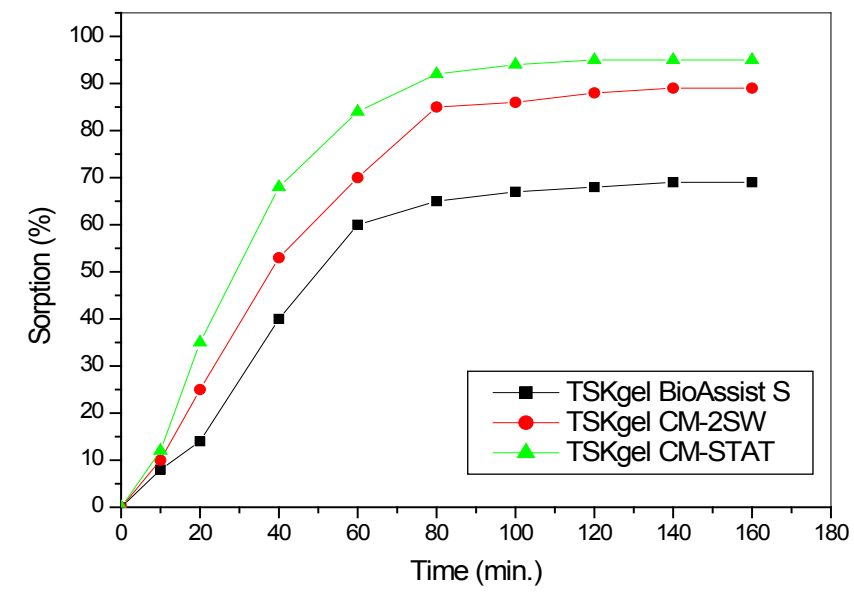

Figure 1: Effect of shaking time on uptake of three metal ions onto different cation exchangers. 


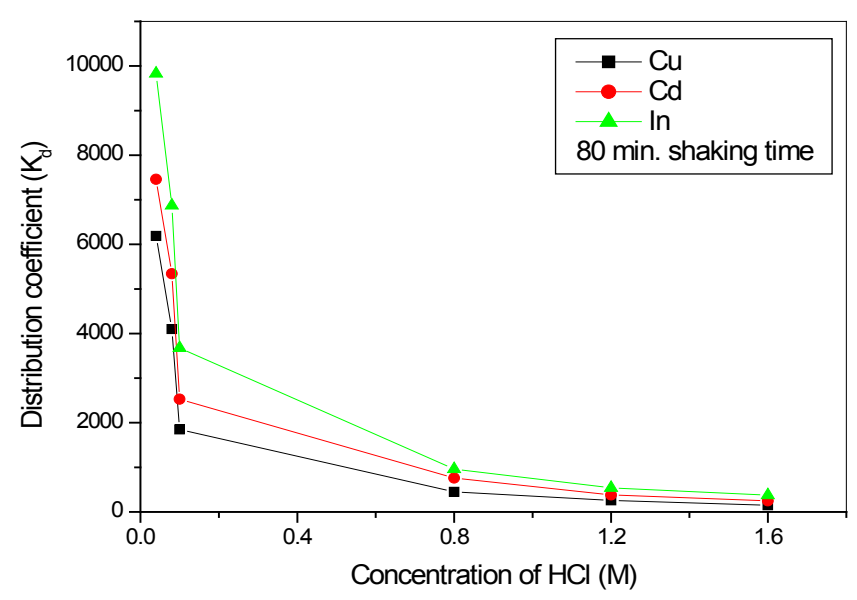

Figure 2: Effect of $\mathrm{HCl}$ concentration on the sorption of metal ions onto TSKgel Bio Assist $\mathrm{S}$ cation exchanger.

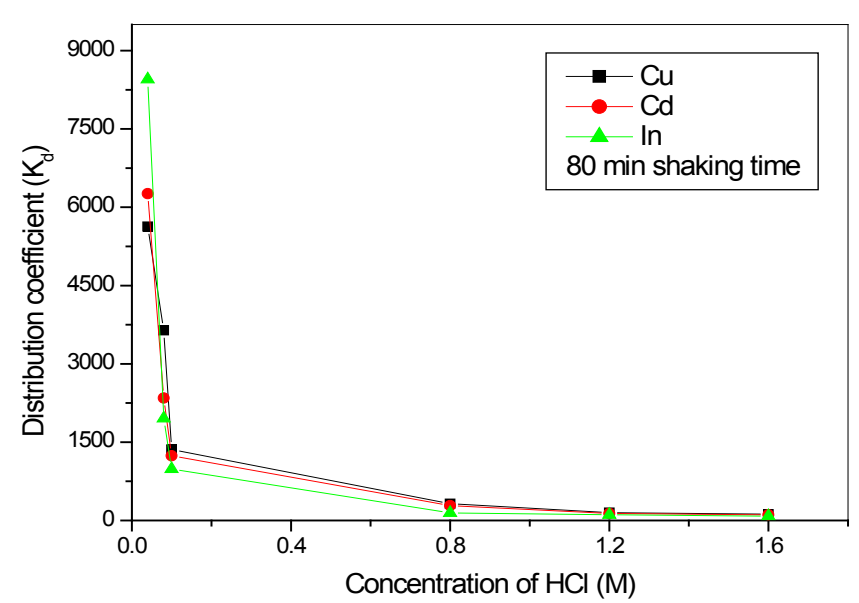

Figure 3: Effect of $\mathrm{HCl}$ concentration on the sorption of metal ions onto TSKgel CM-2SW cation exchanger.

ionization of the exchangeable ions. Worth mention, all ion exchangers indicated sharp decrease in the distribution coefficient at approximately the same acid concentration. This might be due to the independence of exchanging mechanism on the chemical structure of the exchanging groups but mainly on the chemical composition of solution.

Effect of acetate buffer concentration: The distribution coefficient of the studied metal ions was determined at various concentrations of acetate buffer at $\mathrm{pH} 4$. The results showed that, the metal ions were sorbed to a great extent at low concentrations of the buffer within the range 0.01-0.1 mol L-1) as depicted in Figures 5-7. The sorption behavior of ${ }^{111}$ In on three cation exchangers was quite different according to the evaluated $K_{d}$ values. It was found to be 10535,11245 and 8640 for TSKgel BioAssist S, TSKgel CM-2SW and TSKgel CMSTAT, respectively. Therefore, a $0.01 \mathrm{~mol} \mathrm{~L}^{-1}$ concentration of acetate buffer was considered satisfactorily and used as an eluting agent for separation of In from Cd and Cu. Generally, the sorption of all metal ions decreased abruptly with raising the buffer concentration which can be due to the increase in ionic strength of the medium. Copper sorption was the most strongly decreased with adding the buffer where the possibility of formation of copper-acetate complex is expected. Moreover, the charge of the buffering ion should be identical to the ion exchange group because if buffering ions of opposite charge are utilized they may participate in the ion exchange process and cause disturbances to sorption. Thus, use of negatively charged acetate ions as a buffer is suitable for optimizing the sorption conditions.

Effect of EDTA concentration: The purpose of adding the ligand EDTA to the sample is to investigate the competition between the ion exchanger and the ligand on metal ions. The effect of EDTA concentration on the $\mathrm{K}_{\mathrm{d}}$ values of these metal ions is shown in Figures 8-10. It can be observed that, the $\mathrm{K}_{\mathrm{d}}$ for $\mathrm{Cd}$ and $\mathrm{Cu}$ at EDTA concentration of $0.01 \mathrm{M} \mathrm{mol} \mathrm{L}^{-1}$ are very high with values of 12890 and 9750, and 2040 in case of TSKgel BioAssist S, TSKgel CM-2SW and TSKgel CM-STAT, respectively. Therefore, a $0.01 \mathrm{~mol} \mathrm{~L}^{-1}$ solution of EDTA can be used as an eluent in case of TSKgel BioAssist $\mathrm{S}$ and TSKgel CM-2SW cation exchangers to separate ${ }^{111} \mathrm{In}$ from $\mathrm{Cd}^{2+}$ and $\mathrm{Cu}^{2+}$ in aqueous media consisting of a $0.01 \mathrm{~mol} \mathrm{~L}^{-1} \mathrm{HCl}$ or $0.01 \mathrm{~mol} \mathrm{~L}^{-1}$ acetate buffer at $\mathrm{pH} 4$. In case of the three ion exchangers, the distribution coefficient decreased gradually by increasing the EDTA concentration. This explains the competitive reaction between the ligand and the ion exchangers towards metal ions. However, EDTA showed a pronounced effect on the decrease of the sorption and becomes adversely affecting when its concentration exceeded $0.01 \mathrm{~mol} \mathrm{~L}^{-1}$.

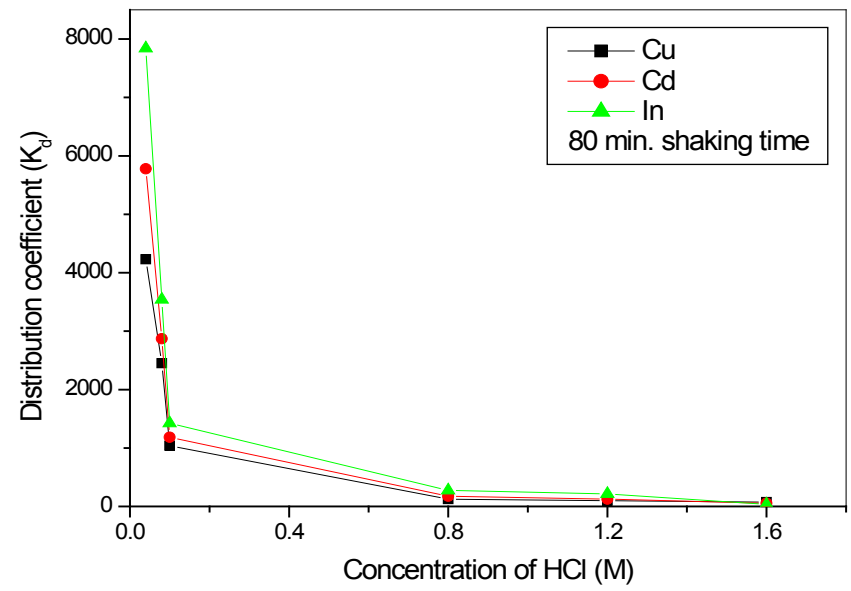

Figure 4: Effect of $\mathrm{HCl}$ concentration on the sorption of metal ions onto TSKgel CM-STAT cation exchanger.

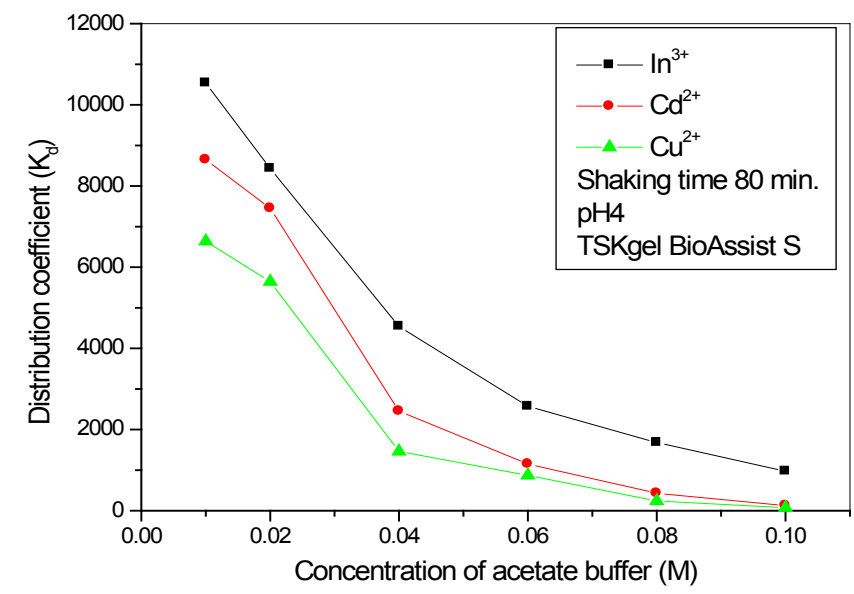

Figure 5: Effect of acetate buffer concentration on the sorption of metal ions onto TSKgel Bio Assist S. 


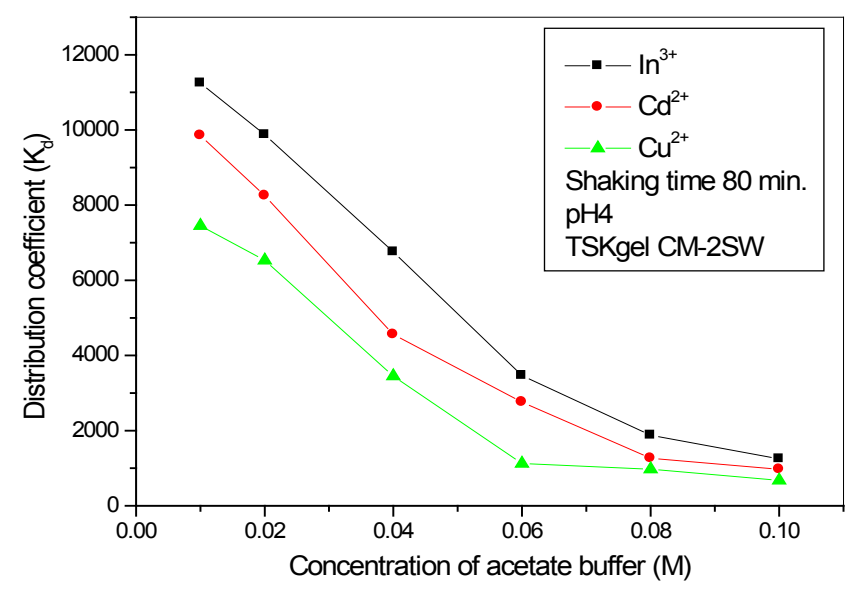

Figure 6: Effect of acetate buffer concentration on the sorption of metal ions onto TS gel CM-2SW.

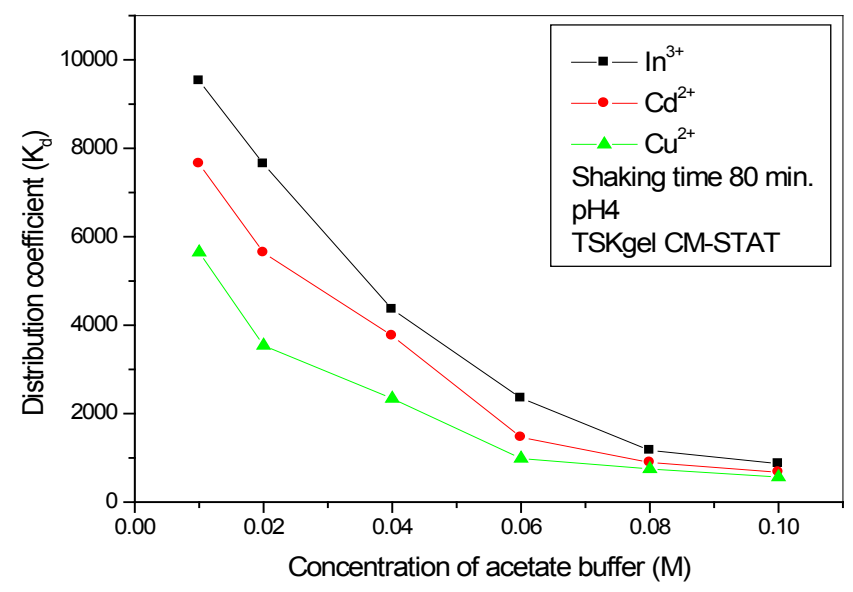

Figure 7: Effect of acetate buffer concentration on the sorption of metal ions onto TSKgel 1q'CM-STAT.

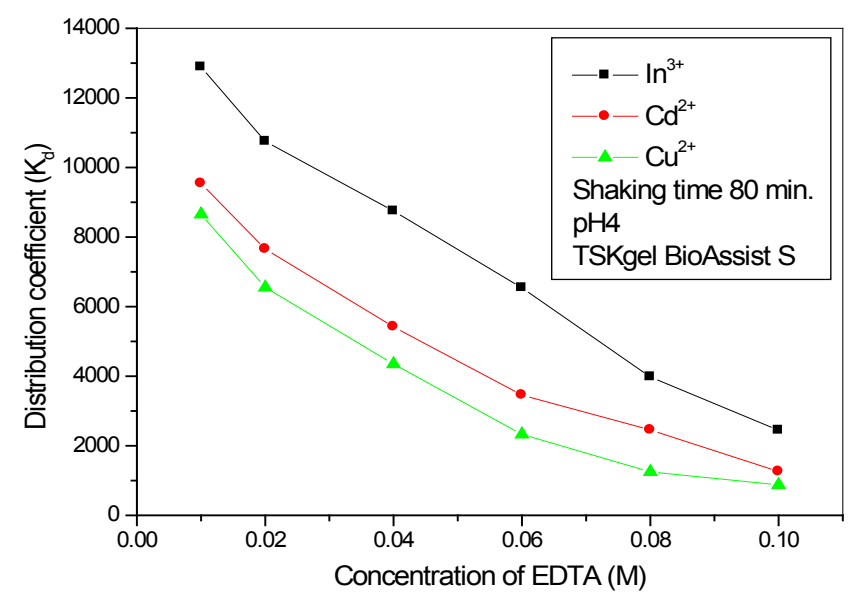

Figure 8: Effect of EDTA concentration on the sorption of metal ions onto TSKgel BioAssist S.

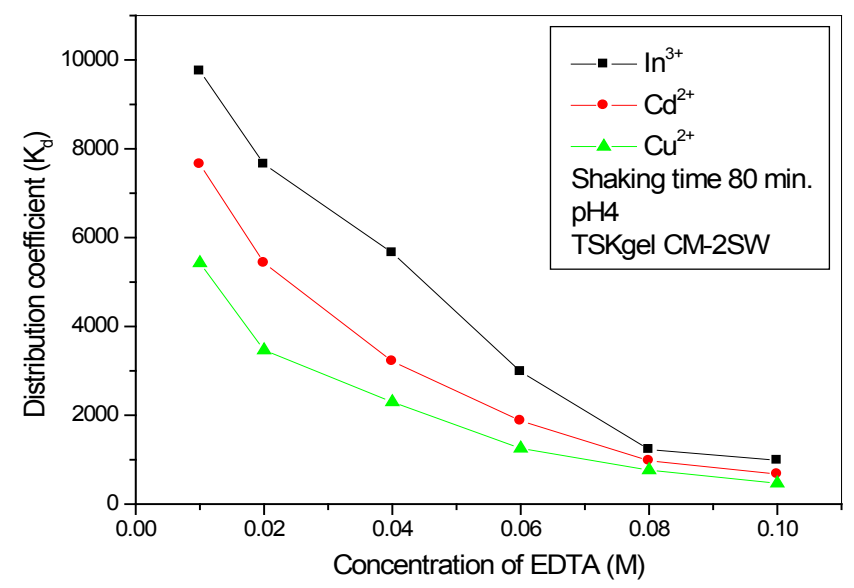

Figure 9: Effect of EDTA concentration on the sorption of metal ions onto TSKgel CM-2SW.

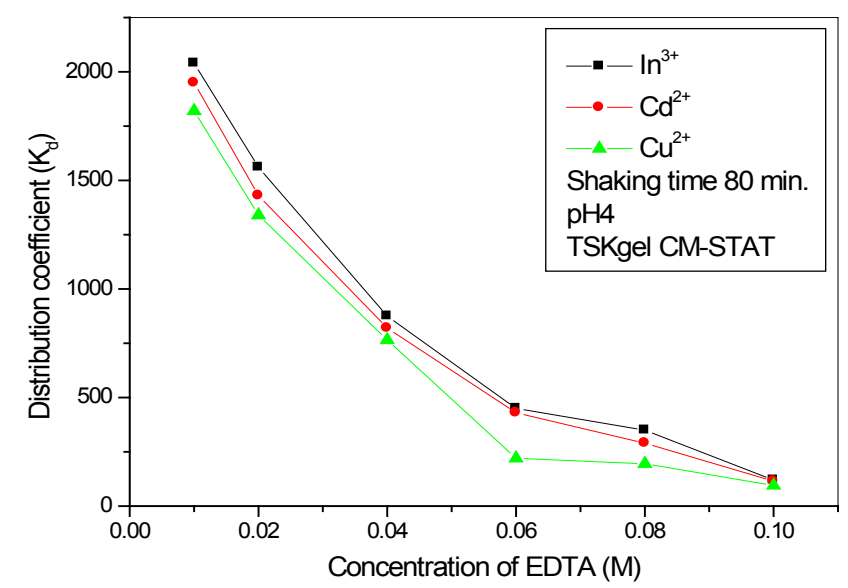

Figure 10: Effect of EDTA concentration on the sorption of metal ions onto TSKgel CM-STAT.

\section{Column experiments}

Breakthrough capacity: The loading capacity of two packed columns with TSKgel BioAssist $S$ and TSKgel CM-2SW cation exchangers used for sorption the ${ }^{111} \mathrm{In}^{3+}$ could be determined from the breakthrough curve.

For this purpose, a glass column with $7 \mathrm{~mm}$ diameter and $12 \mathrm{~cm}$ length was packed with $0.7 \mathrm{~g}$ of dry exchanger. A model solution contains $0.09 \mathrm{~mol} \mathrm{~L}^{-1}$ of inactive indium with a reasonable count of $\mathrm{In}^{111}$ was prepared in $0.01 \mathrm{~mol} \mathrm{~L}^{-1} \mathrm{HCl}$ was passed through the column

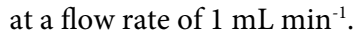

Figure 11 shows the breakthrough curve of $\operatorname{In}^{3+}$ plotted as variation of the concentration of metal in effluent a function of effluent volume. It was observed that in the first $10 \mathrm{~mL}$ of effluent, $\mathrm{In}^{3+}$ ions are completely retained onto the columns. Gradually, the $50 \%$ breakthrough of $\operatorname{In}^{3+}$ occurred at $65 \mathrm{~mL}$, and $45 \mathrm{~mL}$ in case of TSKgel BioAssist S sorbent and TSKgel CM-2SW, respectively.

Elution studies: Elution of indium ions from the packed column TSKgel BioAssist $S$ sorbent or TSKgel CM-2SW was investigated using $0.01 \mathrm{~mol} \mathrm{~L}^{-1}$ of acetate buffer at $\mathrm{pH}$ 4. The obtained results are represented in Figure 12. In case of TSKgel BioAssist S cation 
Citation: Hanafi HA, El-Samad AM (2016) Separation of Cyclotron Produced In-111 (III) from Cadmium (II) and Copper (II) lons Using lon Exchange Technique in Different Media. Chem Sci J 7: 130. doi:10.4172/2150-3494.1000130

Page 5 of 5

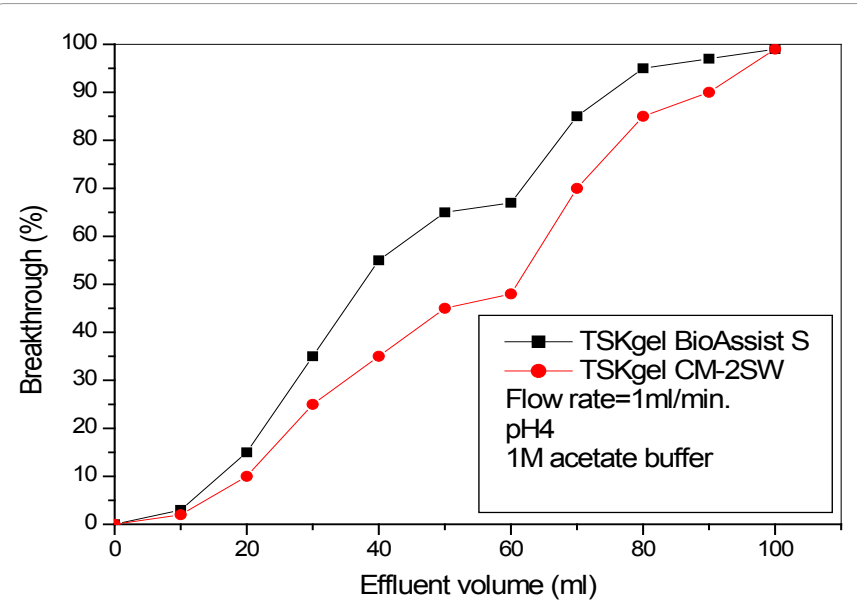

Figure 11: Breakthrough curve of $\mathrm{In}^{3+}$ onto two sorbents in solutions of $0.009 \mathrm{M}$ $\mathrm{In}^{3+}$ dissolved in $1 \mathrm{M} \mathrm{HCl}$.

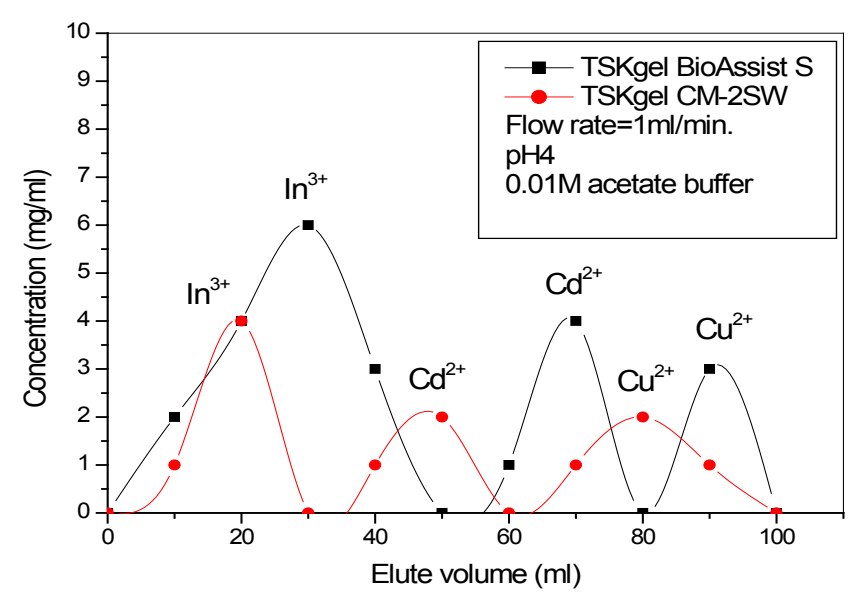

Figure 12: Elution of radioindium from two cation exchangers using $1 \mathrm{M}$ acetate buffer.

exchanger, indium was eluted in the first $30 \mathrm{~mL}$, while cadmium and copper were eluted after 50 and $80 \mathrm{ml}$, respectively.

Whereas, Indium was completely eluted within $20 \mathrm{~mL}$ in case of TSKgel CM-2SW cation exchanger, while, cadmium and copper were eluted after 40 and $70 \mathrm{~mL}$, respectively. Also, the TSKgel BioAssist $\mathrm{S}$ exchanger indicated the ability to separate higher sample concentrations than TSKgel CM-2SW which confirm higher capacity for metal ions. Finally, the separation pattern shows adequate elution conditions and quantitative recovery of the separated elements.

\section{Conclusions}

Comparison between three cation exchangers for the separation of $\mathrm{In}^{111}$ from $\mathrm{Cd}^{2+}$ and $\mathrm{Cu}^{2+}$ was undertaken. It could be concluded that, the TSKgel BioAssist $\mathrm{S}$ is very effective for the separation of $\mathrm{In}^{111}$ from $\mathrm{Cd}^{2+}$ and $\mathrm{Cu}^{2+}$, Also, it could be successfully used to retain the three metal ions from $0.01 \mathrm{~mol} \mathrm{~L}^{-1} \mathrm{HCl}$. Then, $\mathrm{In}^{111}$ was removed in the first $30 \mathrm{~mL}$, followed by $\mathrm{Cd}$ and $\mathrm{Cu}$ at 50 and $80 \mathrm{~mL}$ respectively using 0.01 mol L-1 acetate buffer at $\mathrm{pH} 4$.

\section{Competing Interests}

The authors declare that they have no competing interests.

\section{Author's Contributions}

The authors consider two members in the isotope production unit in cyclotron project-Egyptian Atomic Energy Authority.

\section{Acknowledgements}

This work was funded by the Egyptian Atomic Energy Authority and College of Science, Shaqra University, Saudi Arabia.

\section{References}

1. Varma KR, Shah KB, Mani RS (1980) Studies on the separation of carrier-free indium from cadmium and copper. Radiochemical and radioanalytical letters 43: $255-263$.

2. Das MK, Chattopadhayay S, Sarkar BR, Ramamoorthy N (1997) A cation exchange method for separation of ${ }^{111} \mathrm{In}$ from inactive silver, copper, traces of iron and radioactive gallium and zinc isotopes. Appl Radiat Isot 48: 11-18.

3. Mushtaq A, Karim HMA (1993) Ion Exchange Behaviour of Cadmium and Indium on Organic Anion and Cation Exchangers: A ${ }^{115} \mathrm{Cd} /{ }^{115 \mathrm{~m}} \mathrm{In}$ Generator. Radiochimica Acta 60: 189-196.

4. Azzam A (1999) Factory tests of the physical parameters of the MGC-20 Egyptian Cyclotron. Nuclear Physics Deptartment, NRCAEA, pp: 1-19.

5. Lee JD (1991) Concise Inorganic Chemistry. Fourth Edition. Chapman \& Hall UK.

6. Lahiri S, Maiti M, Ghosh K (2013) Production and separation of ${ }^{111} \mathrm{In}$ : an important radionuclide in life sciences: a mini review. J Radioanal Nucl Chem 297: 309-316.

7. Hanafi HA (2009) A New Cost Technique for Separation of Indium-111. Isotope Produced from Cadmium Target in Low Energy Cyclotron. J Rad Res Appl Sci 2: 69-83.

8. Hanafi HA, Arifi A (2011) Sorption of Ga(III), Cu(II), Ni(II) and Zn(II) on Synthetic Polymeric Resins. Asian Journal of Chemistry 23: 255-259.

9. Bhattacharyya DK, Basu S (1979) Separation of carrier-free ${ }^{115 m} / \mathrm{n}$ from ${ }^{115} \mathrm{Cd}$ and ${ }^{132}$ from ${ }^{132} \mathrm{Te}$ over the zirconium oxide column. Journal of Radioanalytical and Nuclear Chemistry 52: 267-273.

10. Botros N, El-Bayoumy SS, El-Garhy M (1990) lon Exchange Separation of Eu ${ }^{3+}$ from Different Salt Solutions. Isotopenpraxis 26: 399-401.

11. Frank R, Alexander FN, Qaim SM, Ying-Ming T (1997) Appl Radiat Isot 48 19-27.

12. Wendt R, Erwin W, Wong V, Wong F (2007) J Nucl Med 48: 453-461.

13. Yavari R, Khanchi AR (2016) Preparation of ${ }^{111} \mathrm{In}$ using irradiated natural cadmium target for medical applications with a simple ion exchange method. $J$ Radioanal Nucl Chem 307: 355-361.

14. Bìták E, Rurarz E, Mikolajewski S, Wojtkowska J (2007) A new method of pure ${ }^{111}$ In production by proton-induced nuclear reactions with enriched ${ }^{112} \mathrm{Sn}$. Nukleonika 52: 17-27. 